\title{
Categorização do risco de extinção de Dyckia limae L. B. Sm. e Tillandsia catimbauensis Leme, W. Till \& J. A. Siqueira por meio de critérios de distribuição geográfica
}

\author{
Juliano Ricardo Fabricante * \\ Kelianne Carolina Targino de Araújo \\ Jéssica Viviane Amorim Ferreira \\ Raphaela Aguiar de Castro \\ Ana Carolina Coelho Pereira da Silva \\ José Alves de Siqueira Filho \\ Centro de Referência para Recuperação de Áreas Degradadas \\ Universidade Federal do Vale do São Francisco \\ Rodovia BR 407, Km 12, Lote 543, Projeto de Irrigação Nilo Coelho, s/n - C1 \\ CEP 56.300-000, Petrolina, PE - Brasil \\ * Autor para correspondência \\ julianofabricante@hotmail.com
}

Submetido em 06/11/2013

Aceito para publicação em 20/03/2014

\section{Resumo}

Os critérios de distribuição geográfica favorecem a categorização do risco de extinção de espécies pouco conhecidas cientificamente. O objetivo do presente estudo foi de utilizar esses critérios para categorizar as espécies Dyckia limae L. B. Sm. e Tillandsia catimbauensis Leme, W. Till \& J.A. Siqueira. Endêmicas do Parque Nacional do Vale do Catimbau (PARNA do Catimbau), D. limae e T. catimbauensis, tiveram sua extensão de ocorrência e área de ocupação aferidos e os sítios de dispersão ponderados quanto ao seu estado de conservação. As extensões de ocorrência de D. limae e T. catimbauensis foram respectivamente de $15,1 \mathrm{~km}^{2}$ e $22,1 \mathrm{~km}^{2}$, enquanto as áreas de ocupação foram de $5 \mathrm{~km}^{2}$ e $8,5 \mathrm{~km}^{2}$. Em razão destes valores, associado às condições de conservação da localidade, as espécies enquadram-se na categoria “Criticamente em Perigo" (CR).

Palavras-chave: Área de ocupação; Extensão de ocorrência; Lista vermelha

\section{Abstract}

Categorization of risk of extinction of Dyckia limae L. B. Sm. and Tillandsia catimbauensis Leme, W. Till \& J. A. Siqueira by geographical criteria. Geographical distribution criteria are good alternatives for the categorization of endangered species that are little known scientifically. The aim of this study was to use these criteria to categorize the species Dyckia limae L. B. Sm. and Tillandsia catimbauensis Leme, W. Till \& J. A. Siqueira, which are endemic to Valley National Park Catimbau (PARNA Catimbau), D. limae and T. catimbauensis. Their extent of occurrence and area of occupancy were measured and the dispersion sites weighted with respect to the state of conservation. The extent of occurrence of $D$. limae and T. catimbauensis was respectively 15.1 and $22.1 \mathrm{~km}^{2}$, while their area of occupancy was 5 and $8.5 \mathrm{~km}^{2}$. In view of these values, along with the conservation conditions of the locality, the species fall under the category of "Critically Endangered."

Key words: Area of occupancy; Extent of occurrence; Red list 


\section{Introdução}

A maioria dos critérios estipulados para a categorização do risco de extinção de um táxon pela União Internacional para a Conservação da Natureza (IUCN), traz problemas operacionais para localidades em que o conhecimento sobre as espécies são baixos ou inexistentes (ROBBIRT et al., 2006). No geral, eles dependem de informações quantitativas temporais (IUCN, 2010), as quais não são conhecidas para a maioria das espécies brasileiras, especialmente as que ocorrem na Caatinga.

No entanto, existem os critérios de distribuição geográfica: "extensão de ocorrência" e "área de ocupação" (Critérios B - IUCN, 2010). A extensão de ocorrência é definida como a área contida dentro dos limites imaginários traçados que ligam os sítios extremos com a presença do táxon. A área de ocorrência por sua vez, é tida como aqueles sítios que efetivamente apresentam a espécie (IUCN, 2010).

O objetivo do presente estudo foi de utilizar esses critérios para categorizar as espécies Dyckia limae L. B. Sm. e Tillandsia catimbauensis Leme, W. Till \& J. A. Siqueira quanto aos riscos de extinção, com vistas a subsidiar ações de conservação dos táxons e dos seus sítios de distribuição natural.

\section{Material e Métodos}

\section{Espécies estudadas}

Dyckia limae e Tillandsia catimbauensis são bromeliáceas endêmicas do PARNA do Catimbau (SIQUEIRA FILHO; LEME, 2006). Contudo, alguns autores acreditam que $D$. limae pode ter uma ocorrência mais ampla. Na Lista de Espécies da Flora do Brasil (FORZZA et al., 2014) os autores apontam a Paraíba como um outro ponto de registro da espécie.

Dyckia limae inclui plantas terrícolas ou rupícolas, 70-80 cm alt., com 15-20 folhas densamente rosuladas, fortemente coriáceas, suculentas, bainhas mais largas que as lâminas; lâminas triangulares, canaliculadas, fortemente recurvadas unilateralmente, $14-22 \mathrm{~cm}$ compr., 12-15 cm largura e ca. 0,3 cm de espessura próximo à base, verdes, opacas. As inflorescência são eretas, usualmente simples a compostas na base, com 1-2 ramos primários depauperados, $18-25 \mathrm{~cm}$ compr., raque 2-3 mm diâm., ligeiramente flexuosa, roliça, subdensamente lanada e glabrescente. As ca. 17 flores são esparsamente dispostas no ramo terminal, 17-18 mm compr., suberetas a secundas na antese, pedicelos distintos, laranja, subdensamente pálidolanados, 5-6 mm compr., ca. $3 \mathrm{~mm}$ diâm. Sementes complanadas, assimétricas, subcuneadas, base aguda, ca. $5 \mathrm{~mm}$ compr., 3-3,5 mm larg. (SIQUEIRA FILHO; LEME, 2006). Tillandsia catimbauensis inclui plantas rupícolas ou eventualmente epífitas, acaules, 27-30 $\mathrm{cm}$ alt., com ca. 45 folhas ligeiramente secundas, subereto-recurvadas, coriáceas, iguais ou mais curtas que a inflorescência; lâminas estreitamente triangulares, canaliculadas, 18-25 cm compr., ca. $1 \mathrm{~cm}$ larg. na base, densa e grosseiramente cinéreo-escamosas em ambas as faces. Inflorescência simples, oblongo-elipsoide, subereta, projetada lateralmente juntamente com o escapo, densamente florida, 50-65 x $20 \mathrm{~mm}$, raque parcialmente ocultada pelas brácteas, glabra. Flores 9 a 11, polisticamente dispostas, 26-27 mm compr., pedicelos ca. 2,5 mm compr., ca. 2,5 mm diâm. no ápice. Cápsulas desconhecidas (SIQUEIRA FILHO; LEME, 2006).

\section{Área de estudo}

Criado pelo Decreto 913/12 de 13 de dezembro de 2002 (BRASIL, 2002), o PARNA do Catimbau (08³2'54,2”S; 037¹4'49,6”W) compreende uma área de 62.300 ha, nos limites dos Municípios de Tupanatinga, Ibimirim e Buíque, Estado de Pernambuco (BRASIL, 2002). Apresenta flora diversificada, composta por espécies características das Caatingas, e por entidades taxonômicas da Mata Atlântica, Campo Rupestre e Cerrado (RODAL et al., 1998).

O clima regional é o BSh'w (quente e seco), com precipitação e temperatura média anual de $600 \mathrm{~mm}$ e $26^{\circ} \mathrm{C}$ respectivamente (SUDENE, 1990). Os solos predominantes são os Planossolos e Podzólicos nas encostas dos paredões e Litólicos no topo das serras e demais regiões planas (CPRM, 2005). O terreno varia de levemente a fortemente ondulado e apresenta elevado 
número de afloramentos rochosos. A altitude oscila entre 600-1000 m (CPRM, 2005).

\section{Metodologia}

Todo o PARNA do Catimbau e seu entorno foi percorrido e os sítios de ocupação das espécies foram georreferenciados. Adicionalmente, foram anotadas informações a cerca da existência de fatores de pressão antrópica (vilarejos, propriedades rurais, monoculturas e animais de pastoreio) e de indícios de degradação (corte raso da vegetação, queimadas, extração de solos ou rochas e espécies exóticas invasoras) na localidade.

Baseado nas condições de conservação local e nos critérios de distribuição geográfica, as espécies foram enquadradas quanto as suas categorias de ameaça (IUCN, 2010). Para tanto, as áreas de extensão de ocorrência das espécies foram estimadas utilizando o princípio do Mínimo Polígono Convexo (IUCN, 2010). Posteriormente, os polígonos foram gradeados com células de $1 \mathrm{~km}^{2}$, as quais foram divididas virtualmente ao meio (área de $0,5 \mathrm{~km}^{2}$ ). As células com a presença confirmada de $D$. limae e de $T$. catimbauensis foram computadas para a obtenção da área de ocupação de D. limae e de T. catimbauensis (IUCN, 2010). Para a construção dos mapas e estimativas das áreas foi utilizado o software ArcGis 9.3 (ESRI, 2008).

\section{Resultados e Discussão}

\section{Extensão de ocorrência e área de ocupação}

Dyckia limae e Tillandsia catimbauensis ocorrem exclusivamente na região do PARNA do Catimbau caracterizada pelos paredões areníticos e chapadas. Dyckia limae se distribui entre 800-1000 m de altitude, enquanto $T$. catimbauensis é encontrada entre as cotas altimétricas de 850-1000 m. Ambas as espécies são encontradas irregularmente pela área: $D$. limae se dispersa com maior frequência sobre solos expostos e rasos e, em afloramentos rochosos. A espécie também pode ser encontrada em sub-bosques de Caatinga sobre solos arenoquartizolos profundos, porém, menos comumente. Tillandsia catimbauensis, por sua vez, se dispersa principalmente nos paredões. Já nas "cristas" de rochas de arenito, quartzito e feldspato presentes nas chapadas, ela é menos frequente.

A extensão de ocorrência de $D$. limae foi estimada em $15,1 \mathrm{~km}^{2}$, enquanto a área de ocupação em $5 \mathrm{~km}^{2}$ (Figura 1a). Para T. catimbauensis os valores foram de $22,1 \mathrm{~km}^{2}$ e de $8,5 \mathrm{~km}^{2}$ para a extensão de ocorrência e a área de ocupação, respectivamente (Figura 1b). Segundo os critérios B1abiii (extensão de ocorrência) e B2abiii (área de ocupação), as espécies enquadram-se na categoria "Criticamente em Perigo" (CR) (IUCN, 2010).

\section{Considerações sobre as condições de conservação da localidade}

Foram observadas construções rurais (casas, cercas e açudes), monoculturas (milho, feijão, algoroba, mandioca, coco e palma forrageira), áreas de pastagens (gramíneas exóticas) e criação de animais de pastoreio (caprinos, ovinos, bovinos e equinos) em toda a extensão do PARNA do Catimbau, até mesmo, no alto das chapadas. A presença de espécies exóticas é bastante acentuada. No herbário HVASF, por exemplo, estão registradas 27 espécies exóticas provenientes do PARNA do Catimbau (CRIA 2012), dentre as quais Calotropis procera (Aiton) W. T. Aiton, Cenchrus ciliaris L., Melinis repens (Willd.) Zizka, Nicotiana glauca (L.) Grah. e Prosopis pallida (Humb. \& Bonpl. ex Willd.) Kunth, consideradas agressivas invasoras em áreas de Caatinga (FABRICANTE; SIQUEIRA-FILHO, 2012).

Foram observadas dezenas de trilhas que levam turistas informais e moradores a todos os ambientes do parque, incluindo os sítios de ocorrência das espécies estudadas. Nas imediações das trilhas foram encontradas armadilhas para a captura de aves e pequenos mamíferos, assim como indícios de supressão de espécies arbustivoarbóreas.

Estradas vicinais provocam a insularização de ambientes (MORSELLO, 2001), e dão acesso facilitado a regiões de extrema importância para a conservação de espécies endêmicas e raras do local. Um dos limites do PARNA ainda é dado pela BR 110 e existem outras duas rodovias próximas, a BR 232 e a PE 270. 
FIGURA 1: Parque Nacional do Vale do Catimbau (PARNA do Catimbau), Pernambuco. O polígono representa a extensão de ocorrência de (a) Dyckia limae e (b) Tillandsia catimbauensis; as grades representam as células de $1 \mathrm{~km}^{2}$ utilizadas para a estimativa da área de ocupação das espécies.

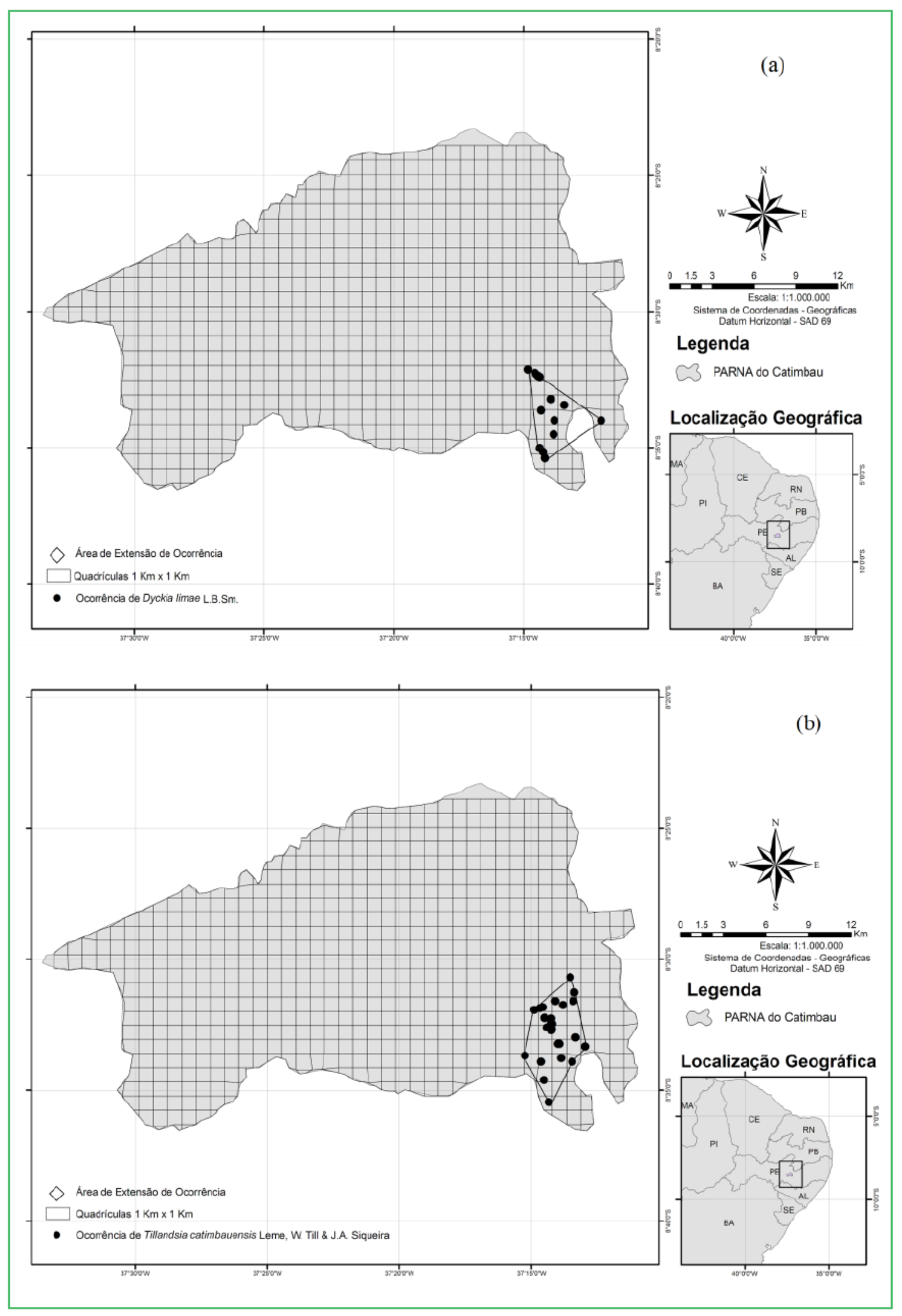


Queimadas em pontos isolados do parque e em seu entorno foram deflagradas durante as expedições. Constatou-se também a ausência de uma zona de amortecimento (Resolução Conama n $13 / 90$ de 06 de dezembro de 1990 - MMA, 1990), o que adiciona problemas para a conservação da localidade (PRIMACK; RODRIGUES, 2005).

Devido à distribuição restrita das espécies (área de extensão de ocorrência menor que $100 \mathrm{~km}^{2}$ e área de ocupação menor que $10 \mathrm{~km}^{2}$ ), associada às condições de conservação do PARNA do Catimbau (extremamente fragmentado, com elevada incidência de fatores de pressão antrópica e contínua perda de qualidade dos seus hábitat), conclui-se que Dyckia limae e Tillandsia catimbauensis correm riscos críticos de extinção na natureza. A restrição ao uso dos recursos naturais e ao acesso a certas regiões do parque, especialmente as áreas de ocupação de $D$. limae e $T$. catimbauensis, deveria ser imediatamente implantada, a fim de se recuperar a qualidade desses ambientes, e evitar novos focos de degradação.

Destaca-se que o fato de existirem outras espécies endêmicas do PARNA do Catimbau (e.g. Acritopappus buiquensis Bautista \& D.J.N. Hind, Jacaranda rugosa A. H. Gentry e Calliandra aeschynomenoides Benth. - SANTOS et al., 2013) é um bom indicativo da sua individualidade como paisagem e reforça a sua importância como unidade de conservação.

\section{Agradecimentos}

Os autores agradecem ao Ministério da Integração Nacional e ao Sr. Francisco de Assis Araújo, chefe do PARNA do Catimbau.

\section{Referências}

BRASIL. Decreto de 13 de dezembro de 2002: Cria o Parque Nacional do Catimbau, nos Municípios de Ibirimirim, Tupanatinga e Buíque, no Estado de Pernambuco, e dá outras providências. Brasília: Diário Oficial da República Federativa do Brasil, Brasília, 2002.

CPRM - SERVIÇO GEOLÓGICO DO BRASIL. Diagnóstico dos municípios de Águas Belas, Buíque, Itaíba, Pedra, Tupanatinga, Venturosa, estado de Pernambuco. In: MASCARENHAS, J.
C.; BELTRÃO, B. A.; PEREIRA, S. N.; MIRANDA, J. L. F. (Ed.). Projeto cadastro de fontes de abastecimento por água subterrânea. Recife: CPRM/PRODEEM, 2005. p. 11.

CRIA - CENTRO DE REFERÊNCIA EM INFORMAÇÃO AMBIENTAL. SpeciesLink. 2012. Disponível em: $<$ http://splink. cria.org.br>. Acesso em: 11 ago. 2012.

ESRI - ENVIRONMENTAL SYSTEMS RESEARCH INSTITUTE. ArcGIS 9.3. Spatial analyst tools. New York: ESRI, 2008.

FABRICANTE, J. R.; SIQUEIRA-FILHO, J. A. Plantas exóticas e invasoras das caatingas do Rio São Francisco. In: SIQUEIRAFILHO, J. A. (Org.). Flora das caatingas do Rio São Francisco. Rio de Janeiro: Andrea Jakobsson Estúdio Editorial, 2012. p. 366393.

FORZZA, R. C.; COSTA, A.; SIQUEIRA FILHO, J. A.; MARTINELLI, G.; MONTEIRO, R. F.; SANTOS-SILVA, F.; SARAIVA, D. P.; PAIXÃO-SOUZA, B.; LOUZADA, R. B.; VERSIEUX, L. Bromeliaceae in Lista de Espécies da Flora do Brasil. 2014. Disponível em: <http://floradobrasil.jbrj.gov.br/jabot/ floradobrasil/FB16592>. Acesso em: 17 fev. 2014.

IUCN - INTERNATIONAL UNION FOR CONSERVATION OF NATURE. Guidelines for using the IUCN red list categories and criteria. Version 8.1. Prepared by the Standards and Petitions Subcommittee, Gland: IUCN, 2010. 85 p.

MMA - MINISTÉRIO DO MEIO AMBIENTE. Resolução CONAMA nº 13/90, de 6 de dezembro de 1990. Dispõe sobre normas referentes às atividades desenvolvidas no entorno das Unidades de Conservação. Brasília: MMA, 1990.

MORSELLO, C. Áreas protegidas públicas e privadas: seleção e manejo. São Paulo: Editora Annablume, 2001. 343 p.

PRIMACK, R. B.; RODRIGUES, E. Biologia da conservação. 6 ed. Londrina: Editora Planeta, 2005. 327 p.

ROBBIRT, K. M.; ROBERTS, D. L.; HAWKINS, J. A. Comparing IUCN and probabilistic assessments of threat: do IUCN Red List criteria conflate rarity and threat? Biodiversity \& Conservation, London, v. 15, n. 6, p. 1903-1912, 2006.

RODAL, M. J. N.; ANDRADE, K. V. A.; SALES, M. F.; GOMES, A. P. S. Fitossociologia do componente lenhoso de um refúgio vegetacional no município de Buíque, Pernambuco. Revista Brasileira de Biologia, São Carlos, v. 58, n. 3, p. 517-526, 1998.

SANTOS, L. L.; ALVES, A. S. A.; OLIVEIRA, L. S. D.; SALES, M. F. Bignoniaceae Juss. no Parque Nacional Vale do Catimbau, Pernambuco. Rodriguésia, Rio de Janeiro, v. 64, n. 3, p. 479-494, 2013.

SIQUEIRA-FILHO, J. A.; LEME, E. M. 2006. Fragmentos de Mata Atlântica do Nordeste: biodiversidade, conservação e suas bromélias. Rio de Janeiro: Andrea Jackobsson Estúdio Editorial Ltda., 2006. 360 p.

SUDENE - SUPERINTENDÊNCIA DO DESENVOLVIMENTO DO NORDESTE. Dados pluviométricos mensais do nordeste, estado de Pernambuco. Série Pluviometria: 6. Recife: SUDENE, 1990. 